\title{
Social Welfare and the Psychology of Food Sharing: Short-Term Hunger Increases Support for Social Welfare
}

\author{
Michael Bang Petersen ${ }^{1}{ }^{*}$, Lene Aarøe ${ }^{1}$, Niels Holm Jensen ${ }^{2}$, and Oliver Curry ${ }^{3}$ \\ ${ }^{1}$ Department of Political Science \& Government, \\ Aarhus University, Aarhus, DK-8000 \\ ${ }^{2}$ Department of Psychology \& Behavioral Sciences \\ Aarhus University, Aarhus, DK-8000 \\ ${ }^{3}$ Institute of Cognitive and Evolutionary Anthropology, \\ University of Oxford, Oxford, OX2 6PN \\ * Corresponding author: Email: michael@ps.au.dk
}

Accepted for publication in Political Psychology

\begin{abstract}
Do politically irrelevant events influence important policy opinions? Previous research on social welfare attitudes has emphasized the role of political factors such as economic self-interest and ideology. Here, we demonstrate that attitudes to social welfare are also influenced by short-term fluctuations in hunger. Using theories in evolutionary psychology, we predict that hungry individuals will be greedier and take more resources from others while also attempting to induce others to share by signaling cooperative intentions and expressing support for sharing, including evolutionarily novel forms of sharing such as social welfare. We test these predictions using self-reported hunger data as well as comparisons of subjects who participated in relevant online studies before and after eating lunch. Across four studies collected in two different welfare regimes - the UK and Denmark - we consistently find that hungry individuals act in a greedier manner but describe themselves as more cooperative and express greater support for social welfare.
\end{abstract}


Public opinion is the foundation of representative democracy — it drives electoral behavior and forms the basis for government formation. Politicians react to and anticipate changes in public opinion and it has an impact on policy, even between elections. This fundamental position of public opinion has naturally given rise to the normative ideal that these opinions are considered and reasoned. Yet, challenges to this ideal have continuously been leveled from empirical research (e.g., Converse 1964; Zaller 1992). Most notably, recent studies suggest that public opinion is influenced by factors that ought to be strictly politically extraneous. For example, incumbents have been shown to gain votes if the local football team wins immediately before the election (Healy, Malhotra, and Mo 2010), and conservative candidates gain if the polling station is located in a church (Rutchick 2010). Here, we deepen this literature on extraneous factors in public opinion by predicting and demonstrating that people's political attitudes fluctuate over the course of the day and that they do so as systematic, replicable responses to a politically extraneous everyday event: eating lunch.

While this possibly provides a devastating challenge to the normative ideal of considered opinions, we contend that this is not merely yet another demonstration of the muddleheadedness of the public (cf. Sniderman, Brody, and Tetlock 1991). Extending the emerging integration of political science and the life sciences (e.g., Alford \& Hibbing 2004; Fowler \& Schreiber 2008; Hatemi and McDermott 2011; Sidanius \& Kurzban 2003; Smith et al. 2011), our analyses provide a window into the deep psychological processes behind political attitudes: we argue that these systematic fluctuations indicate that people's political attitudes emerge from a sophisticated psychology that has, on the one hand, been highly adaptive over the course of human evolution but was, on the other hand, primarily designed to function in contexts very different from modern mass politics (Cosmides and Tooby 2006; Fowler and Schreiber 2008; Petersen 2012). Utilizing evolutionary psychology and focusing on the case of social welfare, we develop a theory of how hunger activates motivations and behaviors designed to acquire resources through others' 
willful sharing — including evolutionarily novel forms of sharing such as social welfare (see also Kurzban 2010; Wang \& Dworak 2010) . Essentially, we argue and demonstrate that hunger creates an impulse to support social welfare and express sentiments associated with welfare support.

In testing our theory, we follow Danziger et al. (2011) and utilize natural experiments in data collection processes. Specifically, we compare the responses of subjects who participated in relevant studies immediately before and after noon, which is when the vast majority of people eat lunch in the sites of our samples (the UK and Denmark). Using this comparison, we demonstrate across three studies that individuals express greater verbal support for sharing in both interpersonal and social welfare contexts before lunch than after lunch. In a final study, we replicate the findings on social welfare attitudes using direct ratings of hunger. These findings suggest that attitudes to modern social welfare piggyback evolved psychological mechanisms for food acquisition, thus highlighting the refined power of extraneous factors in shaping public opinion formation.

\section{The Psychology of Hunger: Take and Get Others to Give}

Anthropological observations suggest that our ancestors would regularly have experienced states of hunger in which they were not able to feed themselves and their families on the basis of returns from individual foraging (e.g., Kaplan et al. 2000;Hawkes et al. 1991; ;Sugiyama 2004). Given this, it is plausible that natural selection sculpted the human psychology to respond to hunger with motivations and behavior that would help the individual acquire food through means other than foraging (Kurzban 2010; Wang and Dvorak 2010). More specifically, an evolutionary perspective on hunger psychology suggests that hungry states should be associated with, first, a basic motivation to obtain resources (greed) and, second, behavioral patterns that over human evolutionary history would have enabled the individual to actually accrue those resources. In this 
regard, hungry individuals have two main strategies open to them: they can take food from others or they can persuade others to give them food peacefully.

Consistent with this view, a large literature in psychology on so-called resourcedepletion has documented substantial psychological effects of temporary fatigue and hunger. This research shows that depletion elicits behavior patterns related to heightened greed, such as decreased self-control and impulse inhibition (e.g., Gailliot et al. 2007; Gailliot and Baumeister 2007 for a recent meta-analysis, see Hagger et al. 2010), increased risk taking (Symmonds et al. 2010), and greater discounting of the future (Wang and Dvorak 2010). Furthermore, this literature has demonstrated that hungry individuals act more antisocially by attempting to keep more resources and taking more from others. For example, hunger and fatigue elicit increased aggressiveness and protectiveness of resources (e.g., DeWall et al. 2008; Gailliot and Baumeister 2007; Hagger et al. 2010), increased aggression and cheating (e.g., Denson et al. 2010; DeWall et al. 2007; DeWall et al. 2008; Stucke and Baumeister 2006), and decreased helping (DeWall et al. 2008, see also Briers et al. 2006). In general, most studies have interpreted these observations as documenting the general constraining effects on the complex cognitive functioning of being depleted of important metabolic resources (DeWall et al. 2008; DeWall et al. 2011; Denson et al. 2010; Gailliot and Baumeister 2007). Yet these observations are equally interpretable as the activation of an adaptive resource acquisition strategy in situations of hunger: taking resources from others.

This strategy, we suggest, co-exists together with another strategy: getting others to give of their resources. Anthropological records of non-modernized societies show that nearly all food exchanges occur peacefully without aggression (Gurven 2004), and evidence from archaeology and primatology suggest that food sharing practices evolved as early as 1.77 million years ago (Hublin 2009), if not earlier (de Waal 1996). Consequently, peaceful food-sharing 
practices beyond kin relations exist in practically all studied non-modernized societies, whereby large game are often shared in a band-wide, egalitarian manner ( e.g., Gurven 2004; Kaplan et al. 2000). Given this, we expect hungry individuals to be motivated to display the kinds of signals that would induce others to share (see, e.g., Vangelisti, Daly, and Rodnick 1991).

Research on cooperation in psychology and economics suggests that optimal strategies for inducing other people to meet requests for help-giving include providing signals of cooperative inclinations, thereby suggesting that one is likely to reciprocate any help on future occasions. Observations from experimental economics, for example, suggest a key driver of cooperative choices in economic games is expected reciprocation; hence, cooperation drops off substantially when cues suggest that reciprocation is less likely (for an overview, see Ostrom and Walker 2005). In interpersonal contexts more generally, signals of cooperative dispositions include overt expressions of agreeableness (Van Hiel et al. 2008; Koole et al. 2001; Ross et al. 2003) and signals of positivity and sympathy toward needy individuals (Feather 2006; Weiner 1995). Through such signals, hungry individuals should be able to increase the sharing of others. Moreover, sharing can be induced by making social responsibility norms and moral obligations salient (e.g., Bicchieri and Chavez 2010; Branas-Garza 2007). Within a community there is a broad range of norms that can be applied in a specific situation and recent theoretical arguments (DeScioli \& Kurzban 2012) and increasing empirical evidence (Kurzban et al. 2011; Petersen 2012b) suggest that individuals strategically seek to raise attention to specific norms through moral displays. Hence, by moralizing sharing (and, hence, tag non-sharers as immoral and 'evil'), hungry individuals can seek to influence the norms governing the behavior of those in possession of resources and, specifically, push their behavior in the direction of sharing.

In sum, we expect hunger to have two main effects. First, as demonstrated in the current psychological literature on resource depletion, hunger possibly triggers anti-social behavior 
designed to take resources from others. Second, as anthropological literature suggests, occurrences of temporary hunger could also activate motivations and behaviors designed to acquire resources through the willful sharing of others. We suggest these effects to be compatible: both reflect selforiented attempts at obtaining resources from others.

\section{Predictions: Hunger in Interpersonal and Political Contexts}

For most of human evolutionary history, sharing systems existed as small-scale interpersonal networks among kin and friends (Kaplan and Gurven 2005; Kelly 1995). Today, the sharing of resources — redistribution — is undertaken on an evolutionarily-unprecedented scale, among strangers, by a highly institutionalized, highly complex system: the welfare state (Esping-Andersen 1990). For evolution to build and sculpt complex psychological mechanisms, numerous generations of stable environmental pressures are required (Tooby and Cosmides 1990). By implication, it is highly unlikely that any dedicated "psychology of the welfare state" exists. Rather, we expect individuals to form opinions about this novel form of income and wealth redistribution using mechanisms selected for the structurally similar ancestral problem of food sharing (Cosmides and Tooby 2006; Petersen 2012; see also Alford \& Hibbing 2004; Fowler and Schreiber 2008; Smith et al. 2011). If so, any factor regulating motivations in the context of interpersonal food sharing should also factor into welfare opinions, including hunger.

Support for social welfare among individuals not presently on welfare (and unlikely to be so in the near future) signals two things of relevance about these individuals: First, it is a signal of cooperativeness. Supporting social welfare provisioning entails that one is willing to pay costs (e.g., in the form of taxation) in order for others to enjoy a benefit (in the form of welfare payments). Trading off own costs and others' benefits in this way is a general cue of cooperative dispositions (Tooby \& Cosmides 2008). Second, researchers are increasingly noting the moralistic 
connotations of political attitudes (Haidt 2012; Kurzban et al. 2011). Supporting social welfare is not just a signal about individual cooperative predispositions but also a declaration of support to a particular normative regime that transfers resources from those with resources to those in need. Both of these features of welfare support are aligned with the predicted motivations underpinning the "get-others-to-give"-strategy in situations of hunger and, hence, we predict that short-term hunger increases support for social welfare and sentiments related to welfare support. In this regard, it is also important to note that neither of these features undercuts the parallel "take-from-others" strategy as the involved displays are fully attitudinal and, hence, does not necessarily involve actual handing over of resources.

This theoretical account is novel in two respects: first, we extend previous research in the resource depletion literature by arguing that hunger might not just decrease self-restraint but also increase overt expressions of commitment to sharing in order to induce others to give resources to the self. Second, we shed novel light on the deep psychology operating behind the formation of social welfare attitudes by arguing that welfare opinions emerge from this hunger-sensitive psychology of food-sharing. The breadth of these contributions implies that we must advance carefully, documenting each step in the theoretical account. Our first two predictions are therefore concerned with the effects of hunger in interpersonal contexts. Our third and final prediction extends our argument to the political context of social welfare opinions.

The first prediction we seek to test is a replication of the interpersonal effect of hunger found in past studies. In interpersonal contexts, we expect hungry people to behave antisocially when facing opportunities to take resources: they will take more resources at the expense of others (Prediction 1). Given that we use a methodologically innovative design to gauge hunger (see below), our ability to replicate this effect is important. In parallel with this traditional effect of hunger, we seek to test our novel claim that hunger also activates sharing-inducing strategies in 
interpersonal contexts. Hence, we predict that, in interpersonal contexts, hungry individuals will simultaneously send "cheap" signals that they are cooperatively inclined (Prediction 2). With Prediction 2, we seek to establish our novel prediction in an interpersonal context. Our final prediction extends this argument to the domain of social welfare attitudes. We predict that hunger creates an impulse to support social welfare and express the sentiments associated with welfare support (Prediction 3).

\section{Research Design: Natural Experiments and Cross-Sectional Studies}

In order to test the hypotheses, we rely on four studies in the form of surveys conducted in Denmark and the UK. The surveys were carried out between 2007 and 2011 and include both surveys fielded to student samples (Studies 1 and 4) and nationally representative samples (Studies 2-3). This research design allows us to test, demonstrate, and replicate our key theoretical argument with a maximum of variation on individual-level socio-demographic and attitudinal factors and across different (national) research contexts maximizing the institutional variation on the welfare issue.

Studies 1-3 utilize naturally occurring variations in the timing of data collection, which allow us to compare the responses of participants immediately prior to lunch to those answering immediately after lunch. Previous research indicates that mealtime patterns set stable circadian clocks that regulate hunger (LeSauter et al. 2009). Consistent with these observations, prior research on resource depletion has applied the time points before and after a meal break as an indicator of whether individuals are in a high or low state of depletion (Danziger et al. 2011: 6889). Thus, building on the recent research of Danziger et al. (2011), we investigate the effect of short-term fluctuations in hunger by taking advantage of naturally occurring variations in the timing of survey response in data collection processes. 
We focus specifically on hunger around noon—as opposed to hunger around breakfast and dinner-because prior research has shown that the hours around noon are characterized by a relatively high stability in diurnal mood, whereas the hours around breakfast and dinner are characterized by strong changes in diurnal mood, reflecting circadian rhythms (Golder and Macy 2011). Thus, choosing the time points around lunch maximizes the opportunities for observing the effects of variation in hunger on the activation of evolved strategies while keeping diurnal mood swings driven by circadian rhythms as constant as possible. Importantly, in both our sites of research—Denmark and the UK — the food break around noon typically takes place between 12 am and $1 \mathrm{pm}$ (see Online Supporting Information SI1 for documentation). The systematic eating patterns around noon in Denmark and the UK provide a unique natural experiment for the largescale investigation of the triggering effects of hunger on strategies designed to alleviate hunger. Specifically, we compare responses provided immediately before lunchtime (higher mean levels of hunger) with responses provided just after lunchtime (lower mean levels of hunger).

The natural experiment only approximates the properties of the controlled experiment (c.f. Robinson et al. 2009: 346), where random assignment creates the comparability from which stimuli-caused effects can be inferred (Cook and Campbell 1979: 6). Consequently, the researcher must take care to explicate the threats to valid causal inference and deal with these threats (Cook and Campbell 1979: 6). To secure internal validity, we have first provided extensive tests of whether our hunger variable tracks other politically relevant demographical variables (see Online Supporting Information SI1). This is not the case. Furthermore, following Danziger et al. (2011), we apply a cautious strategy and include statistical control for the socio-demographic and political background variables traditionally found to influence our variables of interest. Finally, our final study, Study 4, was collected specifically for testing our predictions. In this study, we are able to replicate our key findings from the natural experiments using a cross-sectional study with direct 
hunger measures. As all three of our predictions present clear expectations about the directionality of hunger effects, we rely on one-tailed significance tests unless otherwise noted.

\section{Study 1: Hunger in interpersonal contexts}

Study 1 investigates the effects of hunger in interpersonal contexts. Specifically, using our lunch comparison, Study 1 tests Prediction 1 -replicating the finding that hunger leads to more selfish and risky behavior - and Prediction 2, that hungry individuals should, at the same time, present themselves as being more cooperative.

\section{Methods}

To test Predictions 1-2, we rely on data from a lab experiment conducted in 2010 among male undergraduates recruited by email from a pool of students at a large British research university (see Online Supporting Information SI2 for details on the data collection and the sample). As described above, our main independent variable is simply a dichotomous variable, timing of session, which indicates for each participant whether that participant was part of the pre-lunchtime session (11 am; session timing $=1)$ or the post-lunchtime session $(1 \mathrm{pm}$; session timing $=0),(\mathrm{n}=17$ in each group).

To measure our main dependent variable, we rely on behavior in an experimental game: the Taking Game. The Taking Game is a reversed version of the standard ultimatum bargaining game (Güth et al. 1982). In this game, the participant is asked how much money he wants to take from another player that has been endowed with $£ 15$. The participant is told that this other player similarly decides how much he allows the participants to take, and if the participant takes more than he is allowed, then both players get nothing. If the participant takes less than (or equal to) the amount he is allowed, then he gets that sum. Participants played four rounds of the taking game against different individuals and were told that one of the decisions they made in the 
games played would be put into effect (further information about the game is available in the Online Supporting Information SI2). Importantly, the Taking Game mimics a situation where individuals in situations of resource-scarcity respond when offered resources from others. Hence, our dependent variable for the empirical test of Prediction 1-resource seizing-is their mean response across the four games played.

Our second dependent variable is used to test Prediction 2 (that hungry individuals should present themselves as more cooperative). It consists of responses to the 20-item Agreeableness Scale of the IPIP NEO, which was obtained prior to game play (Goldberg et al. 2006). Agreeableness constitutes a major human personality trait that has massive influence on social behavior (Graziano and Tobin 2009). Importantly, studies indicate a consistent and strong effect of being high in agreeableness on being cooperative (e.g., Van Hiel et al. 2008; Koole et al. 2001; Ross et al. 2003). In this way, a needy individual's agreeableness is one important cue that others would use in deciding whether the individual is sufficiently likely to reciprocate help on future occasions. Thus, in order to induce others to share, hungry individuals should present themselves as agreeable (see Online Supporting information SI3 for further discussion).

As controls, we have some demographic information about the participants available: their age, their self-described social class (working class, lower middle class, upper middle class, or upper class), and their gender (held constant, as all participants are males). To ensure that our comparison does not simply track differences related to age or class, we control for these factors in the analyses. Tests are performed using OLS regression.

\section{Results}

Do hungry individuals try to seize more resources in the Taking Game? Yes. Participants in the prelunchtime session attempted to take significantly more than participants in the post-lunchtime 
session $\left(\mathrm{M}_{\text {pre-lunch }}=£ 7.50 ; \mathrm{M}_{\text {post-lunch }}=£ 5.40 ; \mathrm{p}\right.$-value of difference $=.024$, one-tailed test $)$. This result replicates the finding in the extant literature that individuals in a depleted state make more selfish and risky decisions (e.g. Symmonds et al. 2010). Furthermore, this finding is robust to the inclusion of control for participant age and social class. Hence, after controlling for these variables, the difference between pre-lunchtime and post-lunchtime responses is substantially unaltered (difference $=£ 1.80, \mathrm{p}=.045$, one-tailed test $).$

Do hungry individuals present themselves as more cooperative? Yes. Although depleted individuals behave more selfishly—attempting to take more-they present themselves as more cooperative. Hence, the session correlates with self-reported agreeableness $(r=-.37, p=.016$, one-tailed). Again, these differences are robust to the inclusion of the demographic information related to age and social class. Hence, the correlations between session and agreeableness (after control: $\mathrm{r}=-.31, \mathrm{p}=.045$, one-tailed) are substantially unaltered.

\section{Discussion}

As predicted, hungry individuals take more while presenting themselves as being more cooperative. The study replicates past findings that depletion decreases self-restraint using a new, behavioral measure. In this way, the study establishes the predictive validity of our pre-lunchtime and postlunchtime responses as a proxy for hunger. As described, previous studies have found hunger to make people both more selfish and more risk-seeking. It should be noted that increased taking in the Taking Game can reflect both types of preferences and, hence, we cannot verify whether our proxy for hunger influences both or just one of them.

Importantly, we were able to demonstrate the novel prediction that hunger increases prosocial expressions consistent with our theory. In isolation, however, these results should be interpreted with some caution, because the number of subjects was low and relatively few control 
variables were available to address the potential concerns that there might be other systematic differences between individuals participating before and after lunch. These limitations are addressed in Studies 2-3.

\section{Study 2: Hunger in Political Contexts I}

Study 2 provides our first test of Prediction 3: that support for sharing in situations of hunger extends to the domain of modern social welfare. Study 2 is based on the 2007 Danish National Election online survey. As a general survey of political attitudes and behaviors, this survey contains limited but well-validated measures of individuals' attitudes to social welfare recipients as well as extensive information on demographic background.

\section{Methods and measures}

The 2007 Danish National Election online survey was conducted as a computer-administered web survey and fielded to a nationally representative sample in Denmark (for details on the data collection and sample, see Online Supporting Information SI4). Given the web survey design, information on the exact time at which survey participation was onset was automatically logged. Our main independent variable is a dichotomous variable, timing of response, which indicates for each participant whether that participant started answering the survey between 11 and 12 am (survey timing $=1$ ) or between 1 and 2 pm (survey timing $=0$ ). This comparison leaves us with 586 participants for Study 2.

The dependent variable in Study 2, attitudes toward welfare recipients, is based on answers to two 5-point Likert-format questions, where the respondents were asked to indicate how much they agreed or disagreed with the following statements: "Too many get social welfare without needing it," and "Many of the unemployed don't really want to find work." These are the only items 
in the survey directly relating to whether welfare recipients are morally worthy of being helped or not. The answers to these items are highly correlated $(\mathrm{r}=.44, \mathrm{p}<.001$, two-tailed $)$ and were added together to form a reliable scale of attitudes toward welfare recipients with high values indicating more negative attitudes (“don’t know” answers were excluded).

Importantly, the survey also provides a range of available control variables, allowing us to test the prediction utilizing a maximal control strategy. To ensure that our comparison of prelunchtime and post-lunchtime responses does not track other systematic differences, we control for a large range of standard socio-demographic factors traditionally included in studies of social welfare attitudes. Finally, to maximize control and ensure the internal validity of our analysis, we follow the work of Feldman and Steenbergen (2001) and also include a control for general value predispositions. Specifically, we include control for respondents' general egalitarian values using standard Danish opinion items (cf. Petersen et al. 2010; $\alpha=.62$, see Online Supporting Information SI4 for measurement details).

\section{Results}

Do hungry individuals express more favorable attitudes toward welfare recipients? Yes. As shown in Table 1, respondents answering pre-lunch are significantly more positively disposed toward welfare recipients than post-lunch respondents $(\beta=-.12, \mathrm{p}=.003$, one-tailed $) .{ }^{1}$ In fact, as can be seen from Table 1, pre-lunchtime response is the second strongest predictor of attitudes toward

\footnotetext{
${ }^{1}$ We argue that this effect reflects signals of cooperativeness in situations of hunger. At the same time, given that welfare recipients also constitute a potential outgroup, this effect could also reflect a general tendency to become positive towards members of outgroups in situations of hunger. The Danish National Election Survey contains a number of statements about other potential outgroups including immigrants, criminals and homosexuals. To see whether hunger influences agreement with these other statements over and beyond the effect of hunger on social welfare perceptions, we regress agreement on our hunger measure controlling for welfare perceptions. The analyses, reported in the Online Supporting Information SI5, show that hunger does not influence other perceptions and attitudes about potential outgroups and, hence, document the specificity of the hunger effect on social welfare related perceptions.
} 
welfare recipients, exceeded only by the effect of egalitarian values (see Online Supporting Information SI5 for robustness checks).

- Table 1 about here -

\section{Discussion}

Using a standardized high quality Danish online survey, the emission of cooperative signals in states of temporary hunger was shown to extend beyond the interpersonal context to modern social welfare attitudes. In line with the theoretical argument that modern social welfare attitudes "piggyback" on evolved systems for food sharing, hungry individuals express more positive attitudes toward welfare recipients. Yet such an effect should be viewed as tentative until replicated using independent data. Also, Study 2 utilized a rather limited measure of attitudes toward welfare recipients. Given these concerns, Study 3 aims to replicate the basic effect of hunger on attitudes about social welfare recipients using independent data and a richer set of dependent variables.

\section{Study 3: Hunger in Political Contexts II}

In the autumn of 2010, the YouGov survey agency conducted a large survey on our behalf focusing on attitudes toward welfare recipients and including a range of measures. Based on quota sampling on the dimension of gender, age, and geography, the survey was fielded to an approximately nationally representative sample in Denmark. When Studies 1 and 2 returned positive results, we had the agency attach their log of the timing of each response to the data file to allow for the replication of the findings in Study 2 using the variety of available measures. 


\section{Methods and measures}

Consistent with the procedures in Study 2, the main independent variable, timing of response, is a dichotomous variable with the values of 1, indicating that responses were provided between 11 and $12 \mathrm{am}$, and 0 , indicating that responses were provided between 1 and $2 \mathrm{pm}$. The survey leaves us with a total of 155 respondents for this comparison.

In the survey, there are three measures available that directly tap sentiments and opinions expressed toward individuals on social welfare; that is, expressed perceptions about welfare recipients, expressed affect toward welfare recipients, and expressed associations about welfare recipients (see Online Supporting Information SI6 for all measurement details).

First, two questions were asked regarding perceptions of welfare recipients: "In your opinion, are most people on social welfare making an effort or are they lazy?" and "In your opinion, are most people on social welfare intelligent or unintelligent?" Answers (correlated at $r=.63$ ) were combined into a scale measuring the content of expressed perceptions about welfare recipients with higher values indicating more negative perceptions. These exact measures, in particular perceptions of laziness, have previously been shown to have close links to welfare attitudes such that negative perceptions reduce the support for welfare (Gilens 1999).

Second, two relevant measures of expressed affect toward welfare recipients are available. Hence, respondents were asked about the extent to which they felt anger and compassion "when hearing or reading about people on social welfare." Previous research has linked these emotions to support for welfare such that anger reduces the support for social welfare while compassion increases it (Wiener 1995; Petersen et al. 2012). Answers (correlated at $r=-.35$ ) were combined into a single scale of affect toward welfare recipients with high values indicating high levels of negative affect (i.e., high anger, low compassion). 
Third, the survey respondents completed a free association task about social welfare recipients. Specifically, they were asked to write the words they would use to describe those receiving social welfare. The content of the respondents' associations was coded by two student coders. We tally the number of associations describing social welfare recipients as victims of forces beyond their control, which constitutes the major argument in favor of providing welfare (Petersen 2012).

We are able to control for three basic demographic variables: gender, age, and education level. Furthermore, we again maximize statistical control by including a scale of individual predispositions regarding egalitarianism $(\alpha=.87)$.

\section{Results}

Do hungry individuals express more positive attitudes toward welfare recipients? Yes. As evidenced in Table 2, Model 1, Study 3 replicates the findings from Study 2: there is a clear and highly significant effect of pre-lunchtime response on attitudes to welfare recipients $(\beta=-.14, p=$ .027 , one-tailed). The pre-lunchtime respondents are less negatively disposed toward welfare recipients than the post-lunch respondents. Furthermore, as seen in Table 2, Models 2-3, pre-lunch participants express significantly less negative affect toward welfare recipients $(\beta=-.14, p=.024$, one-tailed) and significantly more associations about welfare recipients as the deserving, unfortunate victims of forces beyond their control $(\beta=.22, \mathrm{p}=.030$, one-tailed). As in Study 2, these effects are robust to the inclusion of the range of control variables.

- Table 2 about here - 


\section{Discussion}

Using a richer set of dependent variables, Study 3 provides several replications of the effect of found in Study 2: that hungry individuals express more positive attitudes toward social welfare recipients. They report more positive perceptions of social welfare recipients, more positive affect toward welfare recipients and they are more likely to associate welfare recipients with being unfortunate.

\section{Study 4: Hunger in Political Contexts III}

In combination, Studies 2-3 provide strong evidence that people express more positive views of needy individuals before lunch than after lunch. While this comparison based on the timing of survey responses works as a natural experiment and, hence, provides significant causal traction, it is still only an indirect measure of hunger. If our interpretation is correct, we should be able to replicate our basic findings using measures that track differences in hunger more directly. This is the aim of Study 4.

\section{Methods and measures}

We sent out an invitation via email to all of the students at the Faculty of Social Sciences at a major Danish research university to participate in a short online survey. 766 students completed the survey (see Online Supporting Information SI7 for more details on the data collection, the sample and measurements).

We obtained two measures of our independent variable, hunger. First, as an indirect measure, we asked how many hours it had been since their last major meal. Second, we asked for direct subjective feelings of hunger using a straightforward question: "How hungry do you feel right now?" 
To measure perceptions of welfare recipients, we included the two items from the Danish National Election Study (Study 2). Again, answers were highly correlated $(\mathrm{r}=.58)$ and combined in a scale with high values indicating more negative perceptions of welfare recipients.

We include control variables relating to gender, age, BMI (see Wang \& Dworak 2010 and Online Supporting Information SI7 for discussion), and general political ideology. Higher values on the ideology scale indicate a more liberal ideology.

\section{Results}

Do hungry individuals express more positive attitudes to social welfare recipients? Yes, they do. In Table 3, Models 1 and 2, we regress views about social welfare recipients on our two different operationalizations of hunger and the control variables.

- Table 3 about here -

In Model 1, there is a significant effect of the number of hours since the last meal on views about social welfare recipients. As expected, people who have eaten more recently express more negative views about welfare recipients $(\beta=-.07, \mathrm{p}=.009)$ In Model 2 , we include the subjects' selfreported level of hunger. As expected, this measure also has a significant effect on subjects' views about welfare recipients such that, as expected, hungrier subjects express less negative views about welfare recipients $(\beta=-.09, \mathrm{p}<.001)$ (for a replicating analysis, see Online Supporting Information SI8).

Does self-reported hunger mediate the impact on attitudes of the number of hours since the last meal? Self-reported hunger is a more direct measure of hunger than hours since the last meal. Theoretically, consuming a meal should influence welfare attitudes because it influences 
feelings of hunger. To test whether self-reported hunger does indeed mediate the impact of consuming a meal, we used structural equation modeling to test the existence of an indirect effect of hours since the last meal through self-reported hunger. The key variables and their relationships in the structural model are presented in Figure 1.

- Figure 1 about here -

As shown in Figure 1, we find the expected relationship between the three variables. There is a significant indirect effect of hours since the last main meal on attitudes to welfare recipients mediated by self-reported hunger $(\beta=-.04, \mathrm{p}=.012)$. Moreover, self-reported hunger fully mediates this relationship between meal consumption and attitudes: when the indirect effect through self-reporting is taken into account, no additional direct effect of meal consumption is found $(\beta=$ $-.03, \mathrm{p}=.205)$

\section{Discussion}

Study 4 demonstrates two important things. First, we have been able to replicate the effect of our pre-lunchtime and post-lunchtime comparison using two more direct measures of hunger: hours since last meal and self-reported current hunger. Second, using structural equation modeling, we have been able to provide evidence that the effects of meal consumption are channeled through feelings of hunger. This provides strong evidence that hunger is in fact a key driver in the empirical patterns observed throughout the studies reported herein.

\section{General Discussion and Conclusion}

In this article, we have for the first time brought psychological research on resource depletion to 
bear on political science by investigating how one of the most basic human drives, hunger, influences the formation of political attitudes. In testing our argument, we followed Danziger et al. (2011) and utilized naturally occurring experiments in data collection processes. By comparing the responses of subjects who participated in relevant studies immediately before and after lunch, we have demonstrated the parallel existence of adaptive aggressive and non-aggressive effects of depletion in an interpersonal context, hereby both replicating and extending past studies of resource-depletion. In line with our predictions, two separate studies demonstrated that these nonaggressive effects generalized to social welfare attitudes such that individuals express more support for providing assistance to social welfare recipients before eating lunch than after having done so. In a final study, we replicated the findings on social welfare attitudes using two more direct measures of hunger. Hence, using a variety of methods and measures, we have provided evidence for our key claim: that hungry individuals signal verbal support for sharing in both interpersonal and political contexts, including evolutionarily novel forms of sharing such as social welfare.

Some caveats are due. First, we have focused on a particular kind of hunger, shortterm hunger. Long-term or extreme hunger could very well have different effects and, in particular, change the trade-offs between aggressive and non-aggressive strategies for food acquisition. Nonaggressive, sharing strategies reflect the existence of surplus food among partners in the social exchange network, which they are willing to cede. In situations of famine with chronic hunger, surpluses are less likely and the value of food increases and, hence, a willfull sharing is less likely to occur. In such circumstances, individuals are predicted to shift to more aggressive strategies. Second, and related to the first point, our results only speak to the average effects of hunger. There would be many individual differences (e.g., relating to the ability to aggressively seize food) that would change the trade-offs between aggressive and non-aggressive strategies (see, e.g., Petersen $2012 b)$ and, hence, make the effects of hunger vary across individuals. Third, we have argued that 
increased support for social welfare in situations of hunger is a "cheap" cooperative signal, aimed at increasing the sharing efforts of others. An alternative interpretation, however, remains. It could be that the feelings of need associated with hunger facilitate empathizing with others in need (such as welfare recipients). In this perspective, the increased support for social welfare would be sincere rather than strategic. It is difficult to disentangle these two arguments in a survey design and, in particular, using self-reported answers. Hence, even if increased social welfare support is a strategic social signal, individuals might introspectively feel that this support is sincere. Hence, as recently argued by evolutionary psychologists (Kurzban 2011; Trivers 2011), a key part of deception would be the suppression of information about the underlying motives: the less accessible information about strategic motives are, the more effectively one can deceive others. In our view, the best way to discriminate between these alternative accounts is to look to real behavior. If hungry individuals sincerely empathize with economically unfortunate individuals, hungry individuals should be willing to pay costs for redistributing money to these individuals. In contrast to this, we found in Study 1 that signals of increased cooperativeness co-occur with less willingness to share actual money. This observation is consistent with other findings in the larger literature on resource depletion that have documented that depleted people are less willing to provide resources to others (Briers et al. 2006; DeWall et al. 2008). In our view, this provides preliminary evidence that increased social welfare support in states of hunger is, in fact, an "cheap" signal of increased sharing motivation.

These findings have central implications for our understanding of public opinion and puzzles in the extant research on social welfare attitudes. In a sense, our results follow the classic line of research (e.g., Converse 1964) emphasizing that citizens are muddle-headed and politically uninterested, Still, we believe that our analyses paint a very different portrait of the modern citizen. In line with recent applications of biological theory to the study of political behavior, our results 
support Aristotle's notion of humans as political animals (Hatemi and McDermott 2011): the human mind comes equipped with psychological mechanisms designed by biological evolution to successfully navigate problems related to intra-group and intergroup cooperation and conflict—and these mechanisms are utilized when individuals make modern political choices (see also Petersen 2012; Smith et al., 2011). Yet because of the differences between ancestral small-scale foraging groups and modern mass politics, these political choices will be influenced by factors that were adaptive to consider ancestrally but might not be today. In this way, our results indicate that citizens are best characterized as ecologically rational: guided by sophisticated mechanisms for social cognition that, on average, produce rational (i.e., adaptive) choices - but only in situations matching the ecology in which the mechanisms evolved.

This perspective provides a deeper understanding of some of the puzzles in the extant research on social welfare attitudes. For example, much prior work has pointed to rational choice theory: that rational considerations among poor segments of society drive the support for redistributive welfare policies (Esping-Andersen 1990; Korpi and Palme 1998). Yet a key challenge for such theories has been that support for welfare schemes extends very much beyond the poor and that, in many countries, the welfare state enjoys widespread support (Larsen 2006; Gilens 1999). Even in liberal welfare states such as the US, high income groups are highly supportive of welfare schemes relating to education, the elderly, health care, and even a range of poverty-related programs (Gilens 1999). One reaction to these findings is to dismiss the role of rationality and instead argue that welfare support is largely driven by symbolic concerns and political values (Sears et al. 1980; Feldman and Steenbergen 2001; Gilens 1999). Other studies, however, suggest that contexts play a key role. Hence, the present findings on the effects of the micro-context of foodintake are paralleled by studies of the effects of macro-context. Kam \& Nam (2008), for example, convincingly demonstrate that opinions on social welfare respond systematically to macroeconomic 
changes. As with psychological hardship in the form of hunger, macroeconomic hardship increases rather than decreases aggregate support for welfare: "when the goings get tough, Americans reach out", as Kam \& Nam conclude (2008: 223).

If our analysis is correct that such contextual effects reflect that welfare attitudes emerge from an evolved food-sharing psychology, this provides a new understanding of welfare support among high income groups. Rather than irrationality, such support might reflect an ecologically rational response to the context in which the underlying psychology evolved. Hence, ancestral foraging was most likely characterized by frequent random reversals in fortune with potentially fatal consequences - the momentarily lucky hunter or even the generally good hunter could not rest assured (Kaplan \& Gurven 2005; Sugiyama 2004). Today, modern resources such as income or wealth are much less prone to fluctuate randomly, thereby rendering the support of high income groups to the welfare state "irrational." Yet from the perspective of ecological rationality, the support of high income groups for risk buffering arrangements such as the welfare state might in fact reflect a sophisticated psychology that is hard-wired to "assume" a world in which resource shortage can strike at any time (see also McDermott, Smirnov, and Fowler 2008). When the rich today support the welfare state, it might be less a reflection of irrationality and more a reflection of a risk-aversive calculus that evolved ancestrally to protect the self against hunger.

\section{References}

Alford, John R. \& John R. Hibbing. 2004. "The Origin of politics: An evolutionary theory of political behavior", Perspectives on Politics 2 (4): 707-723.

Bicchieri, Christine, and Alex Chavez. 2010. "Behaving as Expected: Public Information and Fairness Norms.” Journal of Behavioral Decision Making 23(2): 161-78.

Briers, Barbara, Mario Pandelaere, Siegfried Dewitte, and Luk Warlop. 2006. "Hungry for the 
Money: the Desire for Caloric Resources Increases the Desire for Financial Resources and Vice Versa.”Psychological Science 17(11): 939-943.

Branas-Garza, Pablo. 2007. "Promoting Helping Behavior with Framing in Dictator Games." Journal of Economic Psychology 28(4): 477-86.

Converse, Philip E. 1964. "The Nature of Belief Systems in Mass Publics". In Ideology and Discontent, ed. David E. Apter. New York: Free Press, 206-261.

Cook, Thomas D., and Donald T. Campbell. 1979. Quasi-Experimentation. Design \& Analysis Issues for Field Settings. Boston: Houghton Mifflin.

Cosmides, Leda, and John Tooby. 2006. "Evolutionary Psychology, Moral Heuristics, and the Law.” In Heuristics and the Law, ed. G. Gigerenzer and Christoph Engel (Dahlem Workshop Report 94). Cambridge, MA: MIT Press, 181-212.

Danziger, Shai, Jonathan Levav, and Liora Avnaim-Pesso. 2011. "Extraneous Factors in Judicial Decisions." Proceedings of the National Academy of Sciences of America, 108(17): 6889-92.

Denson, Thomas F., William von Hippel, Richard I. Kemp, and Lydia S. Teo. 2010. “Glucose Consumption Decreases Impulsive Aggression in Response to Provocation in Aggressive Individuals.” Journal of Experimental Social Psychology 46: 1023-8.

DeScioli, Peter and Rober Kurzban. 2012. "A solution to the mysteries of morality". Psychological Bulletin, published online July 2.

De Waal, Frans. 1996. Good Natured. Cambridge, MA: Harvard University Press.

DeWall, C. Nathan, Roy F. Baumeister, Tyler F. Stillman, and Matthew T. Gaillot. 2007. "Violence Restrained: Effects of Self-Regulation and its Depletion on Aggression." Journal of Experimental Social Psychology 43: 62-76.

DeWall, C. Nathan, Roy F. Baumeister, Matthew T. Gailliot, and Jon K. Maner. 2008. "Depletion Makes the Heart Grow less Helpful: Helping as a Function of Self-Regulatory Energy and 
Genetic Relatedness.” Personality and Social Psychology Bulletin 34: 1653-62.

DeWall, C. Nathan, Timothy Deckman, Matthew T. Gailliot, and Brad J. Bushman. 2011. "Sweetened Blood Cools Hot Tempers: Physiological Self-Control and Aggression." Aggressive Behavior 37: 73-80.

Esping-Andersen, Gøsta. 1990. The Three Worlds of Welfare Capitalism. Cambridge, UK: Polity. Feather, Norman T. (2006). "Deservingness and emotions: Applying the structural model of deservingness to the analysis of affective reactions to outcomes." European Review of Social Psychology 17: 38-73.

Feldman, Stanley, and Marco R. Steenbergen. 2001. "The Humanitarian Foundation of Public Support for Social Welfare.” American Journal of Political Science 45: 658-77.

Fowler, James, and Darren Schreiber. 2008. "Biology, Politics, and the Emerging Science of Human Nature.” Science 322(5903): 912-4.

Gailliot, Matthew T., and Roy F. Baumeister. 2007. “The Physiology of Willpower: Linking Blood Glucose to Self-Control.” Personality and Social Psychology Review 11: 303-27.

Gailliot, Matthew T., Roy F. Baumeister, C. Nathan DeWall, Jon K. Maner, E. Ashby Plant, Dianne M. Tice, Lauren E. Brewer, and Brandon J. Schmeichel. 2007. "Self-Control Relies on Glucose as a Limited Energy Source: Willpower is More than a Metaphor.” Journal of Personality and Social Psychology 92: 325-36.

Gilens, Martin. 1999. Why Americans Hate Welfare: Race, Media, and the Politics of Antipoverty Policy. Chicago: University of Chicago Press.

Goldberg, Lewis R., John A. Johnson, Herbert W. Eber, Robert Hogan, Michael C. Ashton, Robert Cloninger, and Harrison G. Gough. 2006. "The International Personality Item Pool and the Future of Public-Domain Personality Measures." Journal of Research in Personality 40: 84-96. 
Golder, Scott A., and Michael W. Macy. 2011. "Diurnal and Seasonal Mood Vary with Work, Sleep, and Daylength Across Diverse Cultures.” Science 333: 1878-81.

Graziano, William G., and Renée M. Tobin. 2009. “Agreeableness.” In Handbook of Individual Differences in Social Behavior, ed. Mark R. Leary and Rick H. Hoyle. New York: Guilford, $46-61$.

Gurven, Michael. 2004. To Give and to Give Not: The Behavioral Ecology of Human Food Transfers.” Behavioral and Brain Sciences 27: 543-83.

Güth, Werner, Rolf Schmittberger, and Bernd Schwarze. 1982. “An Experimental Analysis of Ultimatum Bargaining.” Journal of Economic Behavior and Organization 3: 367-88. Hagger, Martin S., Chantelle Wood, Chris Stiff, and Nikos L.D. Chatzisarantis. 2010. "Ego Depletion and the Strength Model of Self-Control: A Metaanalysis.” Psychological Bulletin 136: $495-525$.

Haidt. Jonathan (2012). The Righteous Mind. Why Good People are Divided by Politics and Religion. New York: Pantheon Books.

Hatemi, Peter K., and Rose McDermott. (ed.). 2011. Man is by Nature a Political Animal. Chicago: University of Chicago Press.

Hawkes, Kristen, James F. O’Connell, Nicholas G. Blurton Jones.. 1991. 'Hunting Income Patterns among the Hadza: Big Game, Common Goods, Foraging Goals and the Evolution of the Human Diet.” Philosophical Transactions of the Royal Society of London B 334: 243-51.

Healy, Andrew J., Neil Malhotra, and Cecilia H. Mo. 2010. "Irrelevant Events Affect Voters' Evaluations of Government Performance." Proceeding of the National Academy of Sciences 29(107): 12804-9.

Hublin, Jean-Jacques 2009. "The Prehistory of Compassion.” Proceedings of the National Academy of Sciences of the USA. 106(16): 6429-6430. 
Kam, Cindy and Yunju Nam. 2008. "Reaching Out or Pulling Back: Macroeconomic Conditions and Public Support for Social Welfare Spending”. Political Behavior 30 (2): 223-258.

Kaplan, Hillard, and Michael Gurven. 2005. "The Natural History of Human Food Sharing and Cooperation: A Review and a New Multi-Individual Approach to the Negotiation of Norms." In Moral Sentiments and Material Interests: On the Foundations of Cooperation in Economic Life, ed. Herbert Gintis, Samuel Bowles, Robert Boyd, and Ernst Fehr. Cambridge, MA: MIT Press.

Kaplan, Hillard, and Kim Hill. 1985. "Food Sharing among Ache Foragers: Tests of Explanatory Hypotheses." Current Anthropology 26: 223-45.

Kelly, Robert L. 1995. The Foraging Spectrum. Diversity in Hunter-Gatherer Lifeways. Washington, DC: Smithsonian Institution Press.

Koole, Sander L., Wander Jager, Agnes E. van den Berg, Charles A. J. Vlek, and Willem K. B. Hofstee. 2001. "On the social nature of personality: Effects of extraversion, agreeableness, and feedback about collective resource use on cooperation in a resource dilemma." Personality and Social Psychology Bulletin 27: 289-301.

Korpi, Walter, and Joakim Palme. 1998. “The Paradox of Redistribution and Strategies of Equality: Welfare State Institutions, Inequality, and Poverty in the Western Countries.” American Sociological Review 63(5): 661-87.

Kurzban, Robert 2010. "Does the Brain Consume Additional Glucose During Self-Control Tasks?" Evolutionary Psychology 8: 244-59.

Kurzban, Robert (2011). Why Everyone (Else) is a Hypocrite. Princeton: Princeton University Press.

Kurzban, Robert, Amber Dukes and Jason Weeden. 2011. "Sex, drugs, and moral goals: Reproductive strategies and views about recreational drugs". Proceedings of the Royal Society 
-B 277: 3501-3508.

Larsen, Christian A. (2006). The Institutional Logic of Welfare Attitudes. London: Ashgate.

LeSauter, Joseph, Nawshin Hoque, Michael Weintraub, Donald W. Pfaff, and Rae Silver. 2009. “Stomach Ghrelin-Secreting Cells as Food-Entrainable Circadian Clocks.” Proceedings of the National Academy of Sciences of Amcerica, 106(32): 13582-7.

McDermott, Rose, James H. Fowler, and Oleg Smirnov. 2008. "On the Evolutionary Origins of Prospect Theory Preferences.”_The Journal of Politics 70(2): 335-50.

Petersen, Michael Bang, Rune Slothuus, Rune Stubager \& Lise Togeby. 2010. "Deservingness versus values in public opinion on welfare: The automaticity of the deservingness heuristic." European Journal of Political Research 50 (1): 24-52.

Petersen, Michael Bang. 2012. "Social Welfare as Small-Scale Help: Evolutionary Psychology and the Deservingness Heuristic.” American Journal of Political Science 56(1): 1-16.

Petersen, Michael Bang. 2012b. "Moralization as protection against exploitation: Do individuals without allies moralize more?" Evolution and Human Behavior, Available Online, DOI: 10.1016/j.evolhumbehav.2012.09.006.

Robinson, Gregory Robinson, John E. McNulty, and Jonathan S. Krasno. 2009. "Observing the Counterfactual? The Search for Political Experiments in Nature." Political Analysis 17: $341-57$.

Ross, Scott R., M. Karega Rausch, and Kelli E. Canada. 2003. "Competition and Cooperation in the Five-Factor Model: Individual Differences in Achievement Orientation.” The Journal of Psychology 137(4): 323-37.

Rutchick, Abraham M. 2010. "Deus Ex Machina: The Influence of Polling Place on Voting Behavior.” Political Psychology 31: 209-25.

Sears, David O., Richard R. Lau, Tom R. Tyler, and Harris M. Allen Jr. 1980. “Self-Interest vs 
Symbolic Politics in Policy Attitudes and Presidential Voting.” American Political Science Review 74: 670-84.

Sidanius, James and Kurzban, Robert. 2003. "Evolutionary approaches to political psychology”. In

D. O. Sears, L. Huddy, and R. Jervis (Eds.), Handbook of Political Psychology (pp. 146-181). Oxford: Oxford University Press.

Smith, Kevin B., Douglas R. Oxley, Matthew V. Hibbing, John R. Alford and John R. Hibbing. 2011. "Linking Genetics and Political Attitudes: Reconceptualizing Political Ideology". Political Psychology 32 (3): 369-397.

Sniderman, Paul M., Richard A. Brody, and Philip E. Tetlock. 1991. Reasoning and Choice: Explorations in Political Psychology. New York: Cambridge University Press.

Stucke, Tanja S., and Roy F. Baumeister. 2006. "Ego Depletion and Aggressive Behavior: Is the Inhibition of Aggression a Limited Resource?” European Journal of Social Psychology 36: $1-13$.

Sugiyama, Lawrence S. 2004. "Illness, Injury, and Disability among Shiwiar Forager-

Horticulturalists: Implications of Health-Risk Buffering for the Evolution of Human Life History”,.American Journal of Physical Anthropology 123: 371-89.

Symmonds, Mkael, Julian J. Emmanuel, Megan E. Drew, Rachel L. Batterham, and Raymond J. Dolan. 2010. "Metabolic State Alters Economic Decision Making under Risk in Humans." PLoS ONE 5(6):e11090.doi:10.1371/journal.pone.0011090

Tooby, John \& Leda Cosmides. 1990. "The past explains the present: Emotional adaptations and the structure of ancestral environments." Ethology and Sociobiology 11: 375-424.

Tooby, John and and Leda Cosmides. 2008. "The evolutionary psychology of the emotions and their relationship to internal regulatory variables." In Handbook of Emotions, 3rd Edition, ed. Michael Lewis, Jeanette M. Haviland-Jones \& and Lisa Feldman Barrett, New York: Guilford 
Press: 114-137.

Trivers, Robert. 2011. The Folly of Fouls: The Logic of Deceit and Self-Deception in Human Life. New York: Basic Books.

Vangelisti, Anita L., John A. Daly, and Janine Rae Rudnick. 1991. "Making People Feel Guilty in Conversation: Techniques and Correlates." Human Communication Research, 18: 3-39.

Van Hiel, Alain, David De Cremer, and Jeroen Stouten. 2008. “The Personality Basis of Justice: The Five-Factor Model as an Integrative Model of Personality and Procedural Fairness Effects on Cooperation.” European Journal of Personality 22: 519-39.

Wang, X.T., and Robert D. Dvorak. 2010. "Sweet Future: Fluctuating Blood Glucose Levels Affect Future Discounting.” Psychological Science 21: 183-8.

Weiner, Bernard. 1995. Judgments of Responsibility. A Foundation for a Theory of Social Conduct. New York and London: The Guilford Press.

Zaller, John R. 1992. The Nature and Origins of Mass Opinion. New York: Cambridge University Press. 
Table 1. Effects of fluctuations in hunger measured as pre versus post-lunchtime survey response on attitudes to social welfare recipients (Study 2)

\begin{tabular}{l|l} 
& $\begin{array}{c}\text { Negative } \\
\text { Attitudes }\end{array}$ \\
\hline Hunger (pre-lunchtime response) & $-.12^{* *}$ \\
Gender (female) & -.02 \\
Age & .09 \\
Education & $-.08^{*}$ \\
Egalitarianism & $-.26^{* * *}$ \\
Personal Income & -.07 \\
Employed in the Public Sector & -.07 \\
Employed in the Private Sector & -.02 \\
Individuals on Public Transfers & \\
Having Pre-School Children & -.11 \\
$\mathrm{R}^{2}$ & -.03 \\
\hline
\end{tabular}

Notes. All entries are standardized regression coefficients from OLS regression analyses. ${ }^{a}$ reference category is self-employed, the category Individuals on Public Transfers include unemployed, students and pensioners. $* \mathrm{p}<.05, * * \mathrm{p}<.01, * * * \mathrm{p}<.001$, all $\mathrm{p}$-values are one-tailed. 
Table 2. Effects of fluctuations in hunger measured as pre versus post-lunchtime survey response on perceptions, affect and associations relating to social welfare recipients (Study 3 )

\begin{tabular}{|c|c|c|c|}
\hline & $\begin{array}{c}\text { Negative } \\
\text { Perceptions }\end{array}$ & $\begin{array}{c}\text { Negative } \\
\text { Affect }\end{array}$ & $\begin{array}{c}\text { Unlucky } \\
\text { Victims } \\
\text { Associations }\end{array}$ \\
\hline Model & 1 & 2 & 3 \\
\hline Hunger (pre-lunchtime response) & $-.14^{*}$ & $-.14^{*}$ & $.22 *$ \\
\hline Gender (female) & $-.13 *$ & -.02 & $-.20 *$ \\
\hline Age & $-.28 * * *$ & $-.18 * *$ & .10 \\
\hline Education & -.05 & $-.14^{*}$ & -.04 \\
\hline Egalitarianism & $-.28 * * *$ & $-.40 * * *$ & $.45^{* * *}$ \\
\hline $\mathrm{R}^{2}$ & .22 & .26 & .25 \\
\hline
\end{tabular}

Notes. All entries are standardized coefficients from OLS regression analyses. ${ }^{a}$ reference category is self-employed, $* \mathrm{p}<.05, * * \mathrm{p}<.01, * * * \mathrm{p}<.001$, all $\mathrm{p}$-values are one-tailed. 
Table 3. Effects of fluctuations in hunger measured as hours since last meal and subjective feelings of hunger on negative attitudes to social welfare recipients (Study 4)

\begin{tabular}{l|c|c} 
& \multicolumn{2}{|c}{ Negative attitudes } \\
Model & 1 & 2 \\
\hline Hours since last meal & $-.07 * *$ & - \\
Self-reported hunger & - & $-.09 * * *$ \\
Gender (female) & $-.09 *$ & $-.09 *$ \\
Age & $-.08 * *$ & $-.09 * *$ \\
BMI & -.03 & -.02 \\
Political ideology & $-.63 * * *$ & $-.63 * * *$ \\
\hline $\mathrm{R}^{2}$ & .44 & .45 \\
\hline
\end{tabular}

Notes. All entries are standardized coefficients from OLS regression analyses. $* \mathrm{p}<.05, * * \mathrm{p}<.01$, $* * * \mathrm{p}<.001$, all $\mathrm{p}$-values are one-tailed. 
Figure 1. Direct and Indirect Effects of Hunger on Attitudes to Welfare Recipients (study 4)

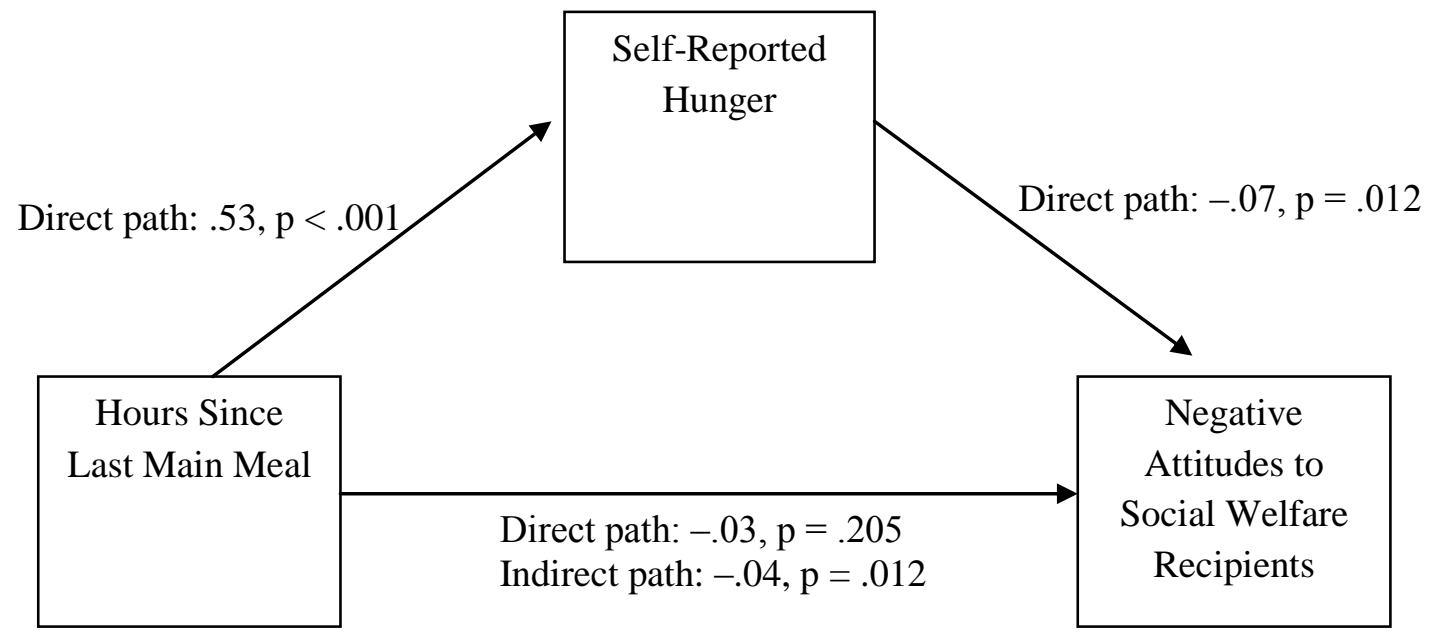

Notes. Standardized path coefficients calculated using Structural Equations Modeling with respondents' gender, age, BMI and general ideology as control variables. All p-values are onetailed. 
